\title{
El cetro de los Átridas y la realeza divina
}

\author{
José Ángel fernandez Canosa *
}

Entonces se levantó el rey Agamenón, empuñando el cetro que Hefesto hiciera para el soberano Zeus Crónida, éste lo dio al mensajero Argicida: Hermes 10 regaló al excelente jinete Pélope, quien, a su vez, lo entregó a Atreo, Pastor de hombres; Atreo al morir lo legó a Tiestes, rico en ganado, y Tiestes lo dejó a Agamenón para que reinara en muchas islas $y$ en todo el pais de Argos ${ }^{1}$.

Como se puede observar, este conocido pasaje de la lliada nos da la línea sucesoria en la posesión del cetro dentro de la familia de los Átridas. Pausanias ${ }^{2}$, por su parte, nos da la misma lista sucesoria que recoge de Homero, informándonos de que tal cetro, al que llaman lanza

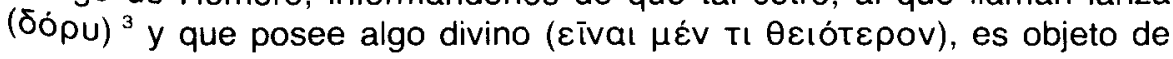

* Universidad de Santiago de Compostela.

'II. II págs. 100-108. La traducción utilizada es la de Luis Segalá Estalella, que será la usada salvo indicación en otro sentido.

2 Paus, IX, 40, 11.

${ }^{3}$ En Roma también originariamente el término utilizado para designar el cetro de los reyes romanos era hasta, según Justino (43, 3: "hastas quas Graeci sceptra dicere..."), siendo el equivalente del dópu griego; cfr. AlfóloI, Andrew, "Hasta-Summa Imperii. The Spear as Embodiment of Sovereignity in Rome», A. J. A. 63 (1959), págs. 1-27. Dentro de todo esto debemos recordar la argentea hasta de Olíndico, celtibero que decia tenerla por entrega de la divinidad y que levantará a gran parte de los celtiberos en una rebelión contra Roma. 
veneración en Queronea, donde es guardado en la casa del sacerdote. Con él se halló oro. Se le hace sacrificios todos los días y le presentan una mesa llena de carne y bollos de todas las clases ${ }^{4}$.

Más frecuentemente que el término óópu se usa otro, que es justamente el que encontramos en el texto homérico mencionado, cuyo origen no es indoeuropeo. Nos referimos a бкn̄mtpov. Es éste un término restringido al griego desde donde pasó al latín y al eslavo ${ }^{5}$. En la realeza homérica es un elemento de indudable importancia para definir al rey,

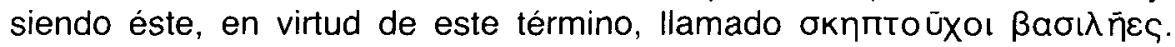

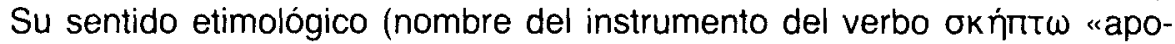
yarse sobre", algo sobre lo que uno deja caer su peso y que impide caerse) poco dice sobre los orígenes de esta insignia. Era el bastón sobre el que el caminante hace su camino. La configuración primera es, para $E$. Benveniste ${ }^{6}$, la del bastón del mensajero. Es el atributo del hombre que marcha para hablar, no para obrar. Las tres condiciones - hombre en marcha, hombre de autoridad, hombre que lleva una palabraconcurren en la persona del mensajero, que es el único que puede explicarlas. Tal instrumento atañe a su función y a su cualidad de signo místico de legitimación, convirtiéndose en personaje sacro cuya misión es la transmisión del mensaje de autoridad ${ }^{7}$. Zeus, por lo tanto, lo da como insignia de legitimación a aquellos que designa para hablar en su nombre ${ }^{8}$.

J. L. Melena organiza su trabajo sobre el cetro en torno a sus virtudes mánticas y que, por lo tanto, es utilizado por aquéllos que practican o tienen tales virtudes: «El cetro, pues, seria el medium transmisor de la inspiración poética que posee al $\mu \mathrm{a}^{\prime} \mathrm{v} \mathrm{TLC}^{\prime}{ }^{9}$. Pero también debe portar consigo una fuerza que dota al $\mu a^{\prime} v \tau$ tı de la inviolabilidad de lo sacro ${ }^{10}$. Ahora bien, ¿qué relación tiene el cetro como útil mántico con la realeza? Con respecto a esto, J. L. Melena sugiere que de la misma manera que el lituus latino tiene un origen claro en el cetro real, algo semejante pudo ocurrir en Grecia ". En efecto, en la Grecia histórica hay huella de la

${ }^{4}$ PAUS, IX, 40, 15.

${ }^{5}$ Benveniste, E., Vocabulario de las instituciones indoeuropeas. Madrid 1983, (París 1969), pág. 256.

${ }^{6}$ Op. cit., pág. 257.

Loc. cit., pág. 257.

8 Ibidem, pág. 258.

9 Melena, J. L., «En torno al oknпtpov homérico", Cuaderios de Filología Clásica, 3 (1972), pág. 323.

${ }_{10}$ Loc. cit., pág. 257.

1 Loc. cit., pág. 257. 
función mántica de la realeza. Herodoto ${ }^{12}$ nos informa de que en Esparta el conocimiento oracular estaba restringido a los miembros de la familia de los Píticos y a los reyes. En Tebas la interpretación de los oráculos estaba reservada a la casa real ${ }^{13}$. En la "época" homérica tampoco faltan reyes que tuviesen poderes mánticos como es el caso de Mérope percosio, de quien se dice que conocía como nadie las artes adivinatorias.

Entre los que utilizaban el cetro se hallaban los heraldos que lo ceden a los jueces en la Bou $\eta^{\prime}$, que lo entregan a los oradores en la asamblea y que lo utilizan en sus misiones como heraldos en las embajadas. No es posible establecer si el cetro del heraldo era un cetro en origen independiente o bien si era un cetro cedido momentáneamente por el monarca ${ }^{14}$. El autor señala que el cetro en manos de los oradores transfiere a estos el don de la palabra por contagio debido a su carácter primitivo de ramo inspirador ${ }^{15}$. En el caso de los gérontes-jueces, se usa Cuando éstos tienen que defender las $\theta \dot{\varepsilon} \mu$ iotع en nombre de Zeus ${ }^{16} \mathrm{y}$ con tal objeto actúa el cetro a fin de darles clarividencia para mantener la $\theta \dot{\varepsilon} \mu \mathrm{ic}$ recta. Originariamente el cetro judicial sería la prolongación del cetro real ${ }^{17}$. Otros usos del cetro los tenemos en los aedos en quienes también concurren inspiración e inviolabilidad ${ }^{18}$ y en los iato quavteıs ${ }^{19}$.

Resume ${ }^{20}$ las diferentes situaciones de los personajes y las virtudes que les proporciona el cetro de la siguiente manera:

1. Inviolabilidad: sacerdote y suplicante, el primero lo usa de manera habitual y el segundo eventual.

2. Clarividencia: mantis, aedo, iatromantis.

3. Clarividencia e inviolabilidad: heraldo y juez, de los que es difícil saber si eran portadores habituales o eventuales; y el rey.

Esta opinión sobre la naturaleza del cetro como donadora de clarividencia e inspiración contrasta con la de $\mathrm{E}$. Benveniste ${ }^{21}$ que reduce el

\footnotetext{
Herod, VI, 57.

PAUS, IX, 26, 3 .

Melena, J. L., Op. cit., pág. 326.

Melena, J. L., Op. cit., pág. 324.

Ibidem, pág. 327.

Ibidem, pág. 329

${ }^{18}$ Ibidem, pág. 332

19 Ibidem, pág. 332 y ss.

${ }^{20}$ Ibidem, pág. 337.

21 Benveniste, E., Op. cit., pág. 257.
} 
cetro al papel de instrumento y don de Zeus que en virtud de su naturaleza de insignia de legitimación cualifica y da los atributos al rey, y al resto de personas que lo necesitan, como los heraldos, para dar un mensaje de autoridad. No obstante, contra la opinión de E. Benveniste que reduce al rey a un portador de la autoridad $y$ al cetro al de elemento simbolizador de ésta, hay que tener en cuenta un modelo mítico de soberania, aquél al que responde la figura de Nereo, el Anciano del Mar, y las relaciones que mantiene con 'A $\lambda \hat{n} \theta \varepsilon ı$ ı.

El carácter de soberano de Nereo es destacado por dos epítetos de significado indudable. Uno de ellos es el de прєбßútaroc que como tal se opone a la $\Gamma \bar{n} \rho a c$, la Vejez maldita, otorgándole a su ancianidad un carácter benéfico. El otro es el de n̈nıoc, que matiza y refuerza el carácter benévolo del primero y que define junto con aquél la naturaleza buena y paternal de $\mathrm{Nereo}^{22}$.

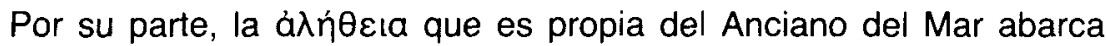
un doble aspecto: primero la potencia mántica de Nereo y, segundo aspecto, su carácter de justiciero, como ejemplificador y administrador de la $\Delta \mathrm{ikń}^{23}$. En ese doble campo en que se encuentra la à $\lambda \dot{\theta} \theta \varepsilon ı$ de Nereo hallamos el tipo particular de justicia que conviene a Nereo. Es la justicia que se hace efectiva por medio de procedimientos judiciales que la adivinación conforma hasta el punto de ser dificil separar adivinación y tales administraciones de justicia. Son estos procedimientos judiciales, además, propios de personajes que tienen una reconocida vinculación con el Mar, como Nereo, como Glauco o como Próteo; son los procedimientos ordálicos, que en Grecia, y a diferencia del Próximo Oriente donde los ríos son los ámbitos físicos de aplicación, se efectúan a través del mar, determinando un tipo de justicia original ${ }^{24}$. Así pues, vemos que el rey no tiene una palabra cuyo respeto sólo le venga otorgado por la autoridad que posee sino que otros elementos intervienen a favor del rey: la mántica y la justicia ordálica trazan la figura de este Buen Rey que es Nereo.

Pero no sólo es la justicia de tipo ordálico la que define al rey. Más allá de la justicia con la que el buen rey bendice su reino ${ }^{25}$, éste en

${ }^{22}$ Detienne, M., Los Maestros de Verdad en la Grecia arcaica. Madrid 1983 (París 1967), pág. 50 ss.

${ }^{23}$ Ibidem, pág. 39 ss.

${ }^{24}$ Ibidem, pág. 43 ss; vid. Glotz, G., La ordalie dans la Grèce primitive. Étude de Droit et de mythologie. Paris 1904.

${ }^{25}$ Véase este conocido pasaje de la Od. XIX 109-114. 
virtud del cetro emite ese conjunto de decretos y juicios que "son especies de oráculos": las $\theta \dot{\varepsilon} \mu t \sigma \tau \varepsilon \varsigma$, cuyo campo de aplicación implica tanto palabras de justicia como las palabras oraculares de Apolo ${ }^{26}$. Es toda una tradición la que vincula la realeza griega con la complementariedad de la mántica y la justicia, tradición de la que Nereo, como también Minos, es sólo una muestra.

En la lliada aparece el cetro asociado constantemente a las $\theta \varepsilon \dot{\varepsilon} \mu \tau_{\tau} \varepsilon$, que junto con aquél son los instrumentos que Zeus pone en las manos del rey:

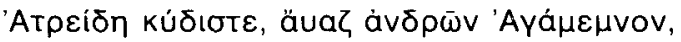
$\dot{\varepsilon} \vee \sigma O l \mu \dot{\varepsilon} \vee \lambda \dot{\eta} \xi \omega$,

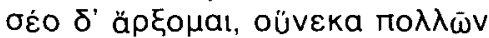

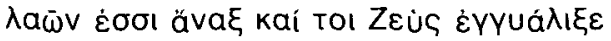

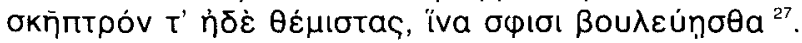

$Y$ tambien:

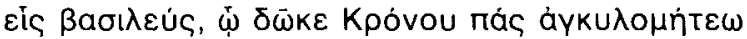

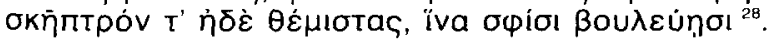

Pues bien, teniendo en cuenta estos elementos y, asimismo, el resto de los que utilizan el cetro, cuyos vínculos con la palabra inspirada son evidentes, creemos que no es posible separar aquél de éstas, a pesar de que es prudente mantener una cierta distancia respecto de las opiniones de J. L. Melena.

El cetro es descrito en su configuración material como hecho de corteza de árbol ${ }^{29}$ que, según Hesíodo ${ }^{30}$, era una rama de laurel. Tenia

${ }^{26}$ Detienne, M., Op. cit., pág. 51 ss.; contra véase DE Romilly, Jaquelinne, La loi dans la pensée grecque. Paris 1971 , pág. 10 para quien las reglas que ordenaban la conducta de los griegos podian ser bien de naturaleza religiosa como los oráculos divinos transmitidos por la tradición sacerdotal, o bien familiar como la $\theta \dot{\varepsilon} \mu ! \varsigma$.

${ }^{27}$ II, IX 96-99.

${ }^{28}$ II, II 205-206.

${ }^{29} / 1,1234$ y ss.

3) Hesiodo, tEOG. 30. 
clavos de oro ${ }^{31}$. Debia ser grueso ${ }^{32}$, y la indicación de Pausanias sobre el cetro guardado en Queronea puede indicar que era largo, pero no es nada seguro. J. L. Melena añade a favor de su longitud la posible se-

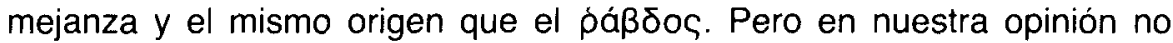

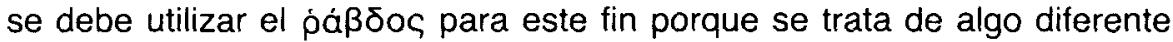
al cetro y nada garantiza que hayan tenido el mismo origen ${ }^{33}$.

También en la llíada encontramos un uso del cetro como objeto sobre el que se hacen juramentos. Héctor, requerido por Dolón para hacer juramento, tomará el cetro y empuñándolo procede a jurar ${ }^{34}$ :

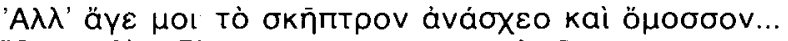

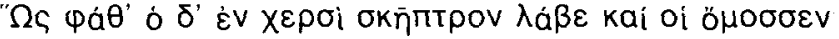

Igualmente hace Agamenón ${ }^{35}$.

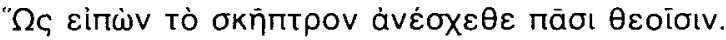

Aclara todo esto el sentido del pasaje en el que Aquiles jura por el cetro $^{36}$ :

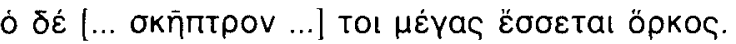

Esto nos lleva a la utilización del cetro como öpкọ que «se coge»

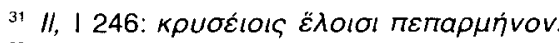

32 II, XVIII 416: пaXú.

${ }^{33}$ Op. cit., pág. 341 y ss.; contra, cf. Benveniste, E., op. cit., pág. 257: «No es, tampoco, una varita mágica: la varita se denomina rhábdos $y$, además, el skêptron nunca es el atributo del mago".

${ }^{34} \mathrm{I}, \times 321,328$.

35 II, VII 412

${ }^{36}$ /I, I 239; cf. Melena, J. L., op. cit., pág. 339. 
en los juramentos, de la misma manera que también el agua de la Estigia sive de öркос a los dioses ${ }^{37}$. E. Benveniste ha señalado que la expresión homérica utilizada para expresar "prestar juramento" (öpkov ópvúval) quería decir "coger» algo concreto, "coger el öркос" "38. Es decir, tener algo aferrado con la mano mientras se pronuncia el juramento, un juramento que puede garantizar que se va a hacer un pacto o que puede garantizar la veracidad de una declaración con respecto a algo pasado como en el juramento judicial ${ }^{39}$. Este juramento pone a los dioses como testigos y garantes del juramento, y hace que ellos sean los vengadores del incumplimiento de éste ${ }^{40}$. Por lo tanto, el cetro también es un instrumento mediador entre los hombres y los dioses en virtud de su potencia para hacer que éstos actúen como garantes de los juramentos.

Para J. L. Melena el cetro hundiría sus raíces en un culto minoico al árbol que, junto con el pilar sacro, los minoicos utilizarian para obtener epifanías de la divinidad. En definitiva, estaria vinculado por su carácter vegetal, por ser su materia prima justamente corteza de un árbol, a un tema universal como el del Árbol Cósmico «cuya característica principal es la de ser el depósito por excelencia de lo sacro», uniendo las regiones infernales y celestes a la humana. Por lo tanto, el poseedor del cetro es un canal de comunicación entre estas tres regiones en virtud del vínculo que tiene con el Árbol Cósmico ${ }^{41}$.

Concluye, pues, J. L. Melena que en un primer momento existiría un portador del cetro que sería hombre divino, rey sacro, sacerdote y Hávtıs, milagrero y salvaguardador de la comunidad en general. En un segundo estadio se produciría una escisión de atribuciones de ese personaje del primer estadio por perderse la noción sacra de la institución real. Posteriormente la división sería mayor dando lugar a los tipos ya vistos anteriormente de magos, clarividentes, sacerdotes, reyes, aedos... ${ }^{42}$.

Esta teoría de la inicial existencia de un personaje en el que concurririan todas estas funciones y que posteriormente se iria dividiendo dando lugar a una especialización de trabajos, no deja de ser atractiva, pero

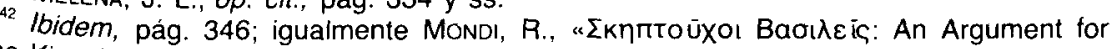
Divine Kingship in Early Greece», Arethusa 13 (1980), pág. 203-216.
} 
desde un punto de vista histórico y con los datos que poseemos no parece verosimil. No hay nada en Grecia, ni en la época micoica ni en la micénica, y mucho menos posteriormente, que permita sostenerla. Es esta teoria una reformulación de la idea del rey mago y del surgimiento de la realeza propuesta por Sir J. G. Frazer ${ }^{43}$. Cuando se habla del rey mago, o del rey con poderes, o aún del rey divino, hay que procurar concretar en qué consisten estos poderes, por lo menos lo más posible; cuando no sea posible concretar, lo más prudente será callar advirtiendo las limitaciones de conocimiento que nos vienen impuestas. Pero decir que un rey es divino ( $y$ bajo este adjetivo se alude a relaciones con la divinidad de carácter diverso) para posteriormente, tomando como excusa este término, vago desde el primer momento, atribuirle toda clase de poderes, no es válido. ¿Cuando se dice que un rey es divino a qué nos estamos refiriendo? ¿Tal vez a un rey «por la gracia de Dios"?, ¿o será a un rey que desciende de la divinidad?; aunque tal vez pudiese ser un rey que es al mismo tiempo dios, o que encarna a la divinidad, o que es un rey taumaturgo como los reyes medievales franceses. Cualquier cosa de éstas puede significar el término, pero en cualquier caso hay que decir en qué sentido es divino, y demostrarlo. Pues bien, si tan difícil es concretar la divinidad del carácter de un rey, mucho más todavia lo será reconstruir la estratigrafía hipotética de una institución, en nuestro caso la realeza, a partir de tan débiles cimientos como son unas cuantas citas unidas sobre la base de una cierta semejanza con un culto, por lo demás no muy bien conocido, que hubo en el mismo ámbito geográfico unos cientos de años antes, postulando la sucesión de uno por otro.

Dentro de este tipo de interpretaciones se encuentra la de quien muestra la semejanza en la concepción biológica de dos reyes (la concepción por medio de una epifanía divina en la que el dios se aparece con la apariencia del marido), mítico uno (Heracles) e histórico el otro (el "faraón» egipcio Hatshepsut), entre dos culturas, la griega y la egipcia, de la que el carácter divino del monarca en vida está sobradamente documentada, y concluir que en la otra cultura, la griega, el rey también era divino en vida y que, además, esta concepción de la monarquía en Grecia sería originaria de Egipto, pues, como es conocido, entre ambos ámbitos hubo relaciones desde tiempos muy tempranos, lo que traería a colación el ver las bases reales de tanto difusionismo en el campo de los 1922).

${ }^{43}$ Vid. de Frazer, J. G., La rama dorada. Barcelona 1981 (resumen, orig. Londres 
estudios sobre las sociedades minoica y heládica reciente ${ }^{44}$. Pero como excedería bastante los objetivos de este estudio no lo vamos a tratar, y si decir, sólo por fijar nuestra posición, que no es lo mismo difundir una mejora técnica en la artesanía cerámica, partiendo de medios de producción de un nivel tecnológico semejante, que traspasar, en contactos que por fuerza debieron ser esporádicos, concepciones teológico-politicas de una cultura a otra. Para esto último se necesitaría un contacto continuado entre las dos culturas, o entre sectores intelectuales de ambas con capacidad para la transmisión de las nuevas ideas a otros sectores de la sociedad, a lo largo de un periodo más bien largo, o la difusión de estas concepciones por medios de comunicación masivos o que permitiesen una cierta continuidad en el trato con las nuevas ideas, además de tener unos buenos traductores y, lo que no es menos importante, haber superado los prejuicios etnocéntricos. Que hubiera algo de esto parece dudoso, si no imposible ${ }^{45}$. Por otra parte, tampoco creemos que sea necesario acudir a la difusión para explicar la coincidencia entre las maneras de ser engendrados de Heracles y de Hatshepsut; llega sencillamente con conjugar la probabilidad, la naturaleza humana y el conocimiento de lo extendido que está la idea de teogamia. En ambos casos se trata de dos teogamias, de las que hay innumerables ejemplos y casos en los mitos y en las creencias a lo largo $y$ ancho de este planeta ${ }^{46}$, de la que una muestra es la que nosotros tenemos en la concepción de Jesús por obra del Espíritu Santo. En ambas, la teogamia se produce bajo una epifanía antropomórfica y en esto tampoco se necesita recurrir a la difusión para explicar la coincidencia pues no re-

\footnotetext{
${ }^{44}$ Vid. WALCOT, Peter, "The Divinity of the Mycenaean King", S.M.E.A. 2 (1967), pág. 53-62. Especialmente aclarativa de la posición del autor es el siguiente fragmento tomado de la página 54: “Un estudio del origen y desarrollo de este mito [... la concepción de Heracles ...] me ha convencido de dos cosas, primero que el rey micénico actuaba de hecho con el rango de dios mientras estaba vivo, y segundo que tal concepto de monarquia fue adoptado por los griegos micénicos de la ideología real del Egipto contemporáneo." Por lo demás, la semejanza con el mundo egipcio ya fue destacada por Herodoto (II, 43), que asociaba el origen y el nombre de este personaje a Egipto, lo que es evidentemente falso pues Heracles es un héroe típico de la "segunda función" indoeuropea, y es con este mundo con el que hay que vincularlo, no con el egipcio. El intento de $P$. Walcot de retrotraer lo mito a la lliada y al "hesiódico" Aspis no es más que una especulación montada sobre lo que los textos no dicen y "lo que posiblemente darian por sobreentendido".

${ }_{45}$ Véase una opinión semejante acerca de la dificultad de este tipo de procesos, pero referido a los comienzos del desarrollo de la filosofía, en M. V. Garcia Quintela, «Problemas para un conocimiento histórico de los presocráticos: el comerciante, el ocioso, el viajero y el filósofo", Actas del 1. ${ }^{\text {er }}$ Congreso Peninsular de Historia Antigua, en Santiago de Compostela, junio de 1986. Santiago 1988, vol. I, pág. 132-134.

${ }^{46}$ Sólo para hacerse una idea de la extensión de este motivo véase la clásica obra de SaINTYves, Pierre, Las madres virgenes y los embarazos milagrosos. Madrid 1985 (París 1908), passim.
} 
sulta extraño que la aparición del dios se produzca bajo forma humana. Teniendo en cuenta la cantidad tan variada de formas que puede adoptar (animales, fenómenos atmosféricos, etc.) nada resulta más natural que un dios "se vista" de hombre para unirse con una mujer y menos, si ésta es tan fiel como Alcmena, que la divinidad adoptase la "forma" de su marido. En fin, que la probabilidad de que algún héroe griego fuese engendrado por un dios que engaña a su madre aparentando ser su marido era bastante alta. Finalmente, hay que recordar que Heracles no se caracteriza en la mitología griega por su actividad como rey, sino por su actividad como guerrero, por lo que tampoco es el mejor ejemplo para desarrollar una teoría como ésta sobre la concepción de la realeza ${ }^{47}$.

Pero retornando al punto del cetro como variante del tema universal del «Árbol sagrado", hay que notar que el hecho de que en la religión minoica hubiese culto a los árboles y al pilar no comporta que tales pilares y tales árboles fuesen ni "Árboles Cósmicos" ni "Pilares Cósmicos", ni que se diese el fenómeno chamánico tan frecuentemente asociado a ellos. Que el cetro fuese de corteza de árbol no lo vincula necesaria e ineludiblemente a tal tipo de "Árbol Cósmico", ni tiene por qué tener el mismo significado. Además, se reconstruye un primitivo significado del cetro a partir de la existencia de una hipotética institución originaria por la pervivencia de un elemento, el cetro, que es precisamente el que hay que aclarar. Es uno de los problemas metodológicos del estratigrafismo cultural, si se nos permite llamarlo de esta manera. Más valía dejar la cosa en lo que conocemos y mientras no tengamos más y mejores datos señalar la posibilidad de que tal vez, y sólo tal vez, pudiese ser así.

Esta teoria del «Árbol Cósmico» procede de M. Eliade ${ }^{48}$, por lo que también nos interesa detenernos por un instante en la exposición de este autor. M. Eliade expone la existencia de un tipo universal, el «Eje Cósmico", que bajo sus diferentes variantes, "Montaña Cósmica", "Árbol Cósmico», "Pilar»..., es la concreción de un lugar simbólico que se encuentra en el centro del mundo y donde es posible, y se realiza, la "ruptura de niveles", es decir, un lugar en el que se produce la comunicación entre las diferentes regiones cósmicas (Cielo, Tierra e Infiernos). El método que sigue consiste en recoger creencias más o menos seme-

${ }_{47}$ Vid. Dumezil, G., El destino del guerrero. México D.F. 1971 (París 1969), pág. 120 129 , especialmente su semejanza con el dios védico Indra.

${ }_{48}$ Vid. para el tema del Árbol Cósmico y el significado que le da ELIADE, M., El chamanismo y técnicas arcaicas del éxtasis. 2. ${ }^{a}$ ed. Madrid 1976 (Paris 1968), fundamentalmente las pág. 213 y ss.; y BUTtERWORTH, E. A. S., The Tree at the Navel of the Earth. Berlin 1977. 
jantes de todo el mundo. No demuestra que todos estos elementos que Se ponen bajo la etiqueta de "ejes cósmicos" tengan más en común que el hecho de ser árboles, pilares o montañas a las que se les atribuyen ciertas virtudes. Por lo demás, en la mayoría de las ocasiones se limita sólo a citar su existencia sin darnos más detalles de su contexto etnológico y religioso, y en escasas ocasiones procede a hacer un análisis dentro del contexto mítico y/o cultural en el que aparece. Sencillamente los etiqueta y expone una teoría que los explicaría a todos. Esto sería válido partiendo del presupuesto de que todos los fenómenos religiosos expresan verdades o sentimientos que son universales debido a la unicidad de la experiencia religiosa. Esta teoria es psicologicista, como to es toda la teoria sobre la religión que sostiene $\mathrm{M}$. Eliade, $y$, sin detenernos en su crítica exhaustiva, diremos que las experiencias religiosas no hunden tanto sus raíces en el fondo de la psique humana como en el fondo de las realidades sociales, de las relaciones del hombre con su sociedad, del hombre con su cultura, en definitiva, en la interacción de los elementos de la sociedad. La explicación de estas experiencias hay que hacerla, por lo tanto, desde una perspectiva sociológica. Las sociedades son distintas y heterogéneas, las experiencias religiosas también. No existe, pues, una cosa tal como la unicidad de la experiencia religiosa, sino experiencias religiosas múltiples que cada hombre y cada sociedad vive de acuerdo con los instrumentos que le suministra su cultura y que le son propios.

El cetro, hasta donde hemos visto, se mueve en el ámbito de la representación de una realeza que evoca por una parte la idea de riqueza y su consecución, y por otra la palabra inspirada para gobernar. La consecución de la riqueza, la fecundidad, son valores asociados al buen rey bajo cuyo buen gobierno, en el que reina la justicia, la tierra es fecunda y los rebaños numerosos. Esta idea, por lo demás, posiblemente sea heredada de los indoeuropeos, entre los que, aunque no de manera exclusiva, se encuentran asociados ambos conceptos:

Indra, viendo que todos los reyes Ksatriya gobernaban sus reinos muy virtuosamente, derramó lluvias vivificantes en el tiempo adecuado y en lugar adecuado y protegió a todas las criaturas ${ }^{49}$.

${ }^{49}$ Mahābhārāta 1, 64, 16. 
El reino de la justicia está donde se mantienen y respetan las $\theta \varepsilon \dot{\mu} \mu$ เ $\varepsilon \varsigma$ que junto con el cetro fueron dados por Zeus al rey, de forma que mantenga la $\theta \dot{\varepsilon} \mu l \varsigma$ recta. Ambas ideas, riqueza y palabra inspirada son definitorias de los reyes descendientes de Pélope: Atreo y Tiestes que destacan como reyes ricos en ganado, y Piteo como rey de verbo inspirado. 